\title{
Salicylic Acid Biosynthetic Genes Expressed in Pseudomonas fluorescens Strain P3 Improve the Induction of Systemic Resistance in Tobacco Against Tobacco Necrosis Virus
}

\author{
M. Maurhofer, C. Reimmann, P. Schmidli-Sacherer, S. Heeb, D. Haas, and G. Défago
}

First, third, and sixth authors: Institute of Plant Science/Phytopathology, Swiss Federal Institute of Technology, CH-8092 Zürich; and second, fourth, and fifth authors: Institute de Biologie Microbienne, Université de Lausanne, CH-1015 Lausanne, Switzerland. Accepted for publication 24 March 1998.

\begin{abstract}
Maurhofer, M., Reimmann, C., Schmidli-Sacherer, P., Heeb, S., Haas, D., and Défago, G. 1998. Salicylic acid biosynthetic genes expressed in Pseudomonas fluorescens strain P3 improve the induction of systemic resistance in tobacco against tobacco necrosis virus. Phytopathology 88 : 678-684.

Application of salicylic acid induces systemic acquired resistance in tobacco. $p \operatorname{ch} A$ and $p \operatorname{ch} B$, which encode for the biosynthesis of salicylic acid in Pseudomonas aeruginosa, were cloned into two expression vectors,

tion in vitro and significantly improved its ability to induce systemic resistance in tobacco against tobacco necrosis virus. Strain CHA0 is a welldescribed biocontrol agent that naturally produces salicylic acid under conditions of iron limitation. Introduction of pchBA into CHA0 increased the production of salicylic acid in vitro and in the rhizosphere of tobacco, but did not improve the ability of $\mathrm{CHAO}$ to induce systemic resistance in tobacco. In addition, these genes did not improve significantly the capacity of strains P3 and CHA0 to suppress black root rot of tobacco in a gnotobiotic system.
\end{abstract} and these constructs were introduced into two root-colonizing strains of P. fluorescens. Introduction of pchBA into strain P3, which does not produce salicylic acid, rendered this strain capable of salicylic acid produc-

Plant growth-promoting rhizobacteria (PGPR) suppress a variety of root and vascular diseases caused by soilborne pathogens $(7,43)$. PGPR suppress disease by antagonizing pathogens via different mechanisms such as antibiosis, competition for iron or carbon, and production of lytic enzymes. PGPR also activate plant defense resulting in systemic protection against different fungal, bacterial, and viral pathogens $(1,9,25,29,32,38,42)$, a phenomenon termed induced systemic resistance (ISR) (19).

The O-antigenic sidechain of outer membrane lipopolysaccharide appears to be essential for the induction of systemic resistance by Pseudomonas fluorescens strains WCS417r and WCS374 in radish against Fusarium wilt $(23,24)$. Press and Kloepper (30) reported that cell wall constituents and membrane fractions of $P$. fluorescens 89B-61 caused ISR against anthracnose in cucumber plants.

PGPR-mediated ISR may be affected by iron availability. For example, the ability of Serratia marcescens 90-166 to induce resistance in cucumber decreased with increasing iron concentration in the fertilizer (31). Some Pseudomonas strains reduced Fusarium wilt of radish more effectively when iron availability in the nutrient solution was low (23). P. aeruginosa 7NSK2 triggered ISR against Botrytis cinerea in bean when the bacterium was cultivated on iron-poor, but not on iron-rich, media (9). These findings suggest that bacterial siderophores, which in general are produced under conditions of iron limitation, might be involved in ISR.

PGPR of the genus Pseudomonas can produce several siderophores such as pyoverdine (pseudobactin), pyochelin, and salicylic acid (SA) $(9,23,27)$. Purified pyoverdine from $P$. fluorescens WCS374 induced resistance in radish against Fusarium wilt (23).

Corresponding author: M. Maurhofer

E-mail address: monika.maurhofer@ipw.agrl.ethz.ch

Publication no. P-1998-0430-02R

(C) 1998 The American Phytopathological Society
Additional keywords: Nicotiana glutinosa, N. tabacum, plant growthpromoting rhizobacteria, strain improvement, Thielaviopsis basicola.

In an earlier study, we found that a pyoverdine-negative mutant of P. fluorescens strain CHA0 lost part of its ability to induce systemic resistance in tobacco against tobacco necrosis virus (TNV) (25).

SA injected into stems, sprayed onto the entire plant, or applied to the roots is a potent inducer of systemic resistance and pathogenesis-related (PR) proteins $(10,23,41,44)$. Therefore, SA produced by PGPR in the rhizosphere may be involved in ISR. De Meyer and Höfte (9) found that SA produced by $P$. aeruginosa 7NSK2 was important in the induction of systemic resistance against $B$. cinerea in bean.

The aim of this study was to determine whether the introduction of the SA biosynthetic genes $p c h B A$ from $P$. aeruginosa PAO1 into $P$. fluorescens strains P3 and CHA0 could improve their ability to induce systemic resistance in tobacco against TNV and suppress black root rot of tobacco. $p c h B A$ were placed under control of a constitutive promoter allowing iron-independent production of SA. $p c h B A$ are part of the $p c h D C B A$ operon required for pyochelin biosynthesis in $P$. aeruginosa PAO1 (36). The $p c h A$ gene product is an isochorismate synthase converting chorismate to isochorismate, and the $p c h B$ gene product is an isochorismate-pyruvate lyase catalyzing the formation of SA from isochorismate (35; C. Gaille and D. Haas, unpublished data). P. fluorescens P3 is SAnegative and a poor biocontrol agent $(25,40)$, whereas $P$. fluorescens CHA0 produces SA under the condition of iron limitation, is a good biocontrol agent of various soilborne pathogens (6), and induces systemic resistance in tobacco against TNV (25). In addition to the siderophores pyoverdine, pyochelin, and SA, strain CHA0 produces hydrogen cyanide and the antibiotics 2,4-diacetylphloroglucinol and pyoluteorin $(6,27)$.

\section{MATERIALS AND METHODS}

Organisms, plasmids, and culture conditions. Wild-type strains of $P$. fluorescens CHA0 and P3 $(37,40)$ were used throughout this study, except for experiments conducted in autoclaved Eschikon 
soil when rifampicin-resistant mutants were used. Plasmids pVK100 (20) and pBBR1MCS (22) served as cloning vectors in Escherichia coli $\mathrm{DH} 5 \alpha$ (33). Bacteria were routinely grown in nutrient yeast broth (Difco nutrient broth [Difco Laboratories, Detroit], $25 \mathrm{~g}$; Difco yeast extract [Difco Laboratories], $5 \mathrm{~g}$; and double-distilled $\mathrm{H}_{2} \mathrm{O}, 1$ liter) and on nutrient agar plates (Oxoid blood base agar [Oxoid Ltd., Basingstoke, Great Britain], 40 g; Difco yeast extract, $5 \mathrm{~g}$; and double-distilled $\mathrm{H}_{2} \mathrm{O}, 1$ liter). For disease suppression assays, bacteria were grown on King's B agar (18); bacteria added to soil were prepared as described earlier $(17,25)$. Antibiotics, when required, were added to the growth media at the following concentrations: tetracycline, $25 \mu \mathrm{g} / \mathrm{ml}$ for E. coli and $125 \mu \mathrm{g} / \mathrm{ml}$ for $P$. fluorescens; chloramphenicol, $50 \mu \mathrm{g} / \mathrm{ml}$ for $E$. coli; kanamycin, $25 \mu \mathrm{g} / \mathrm{ml}$ for $E$. coli; and rifampicin, $100 \mu \mathrm{g} / \mathrm{ml}$ for $P$. fluorescens.

Thielaviopsis basicola (Berk. \& Broome) Ferraris strain ETH D127 was grown on malt agar (Oxoid malt extract [Oxoid Ltd.], $15 \mathrm{~g}$; Oxoid bacteriological agar [Oxoid Ltd.], $12 \mathrm{~g}$; and doubledistilled $\mathrm{H}_{2} \mathrm{O}, 1$ liter) at $24^{\circ} \mathrm{C}$ for 3 weeks in the dark. Endoconidia that developed were suspended in sterile double-distilled water, separated from the chlamydospores and mycelium by filtration through sterile glass wool, and immediately added to the soil to give a concentration of $2 \times 10^{4}$ endoconidia per $\mathrm{g}$ of soil.

TNV (strain 152; Eidgenössische Forschungsanstalt für Agrarökologie and Landbau, Zürich-Reckenholz, Switzerland) was stored on dried infected tobacco leaves at $4^{\circ} \mathrm{C}$. TNV was multiplied on Nicotiana tabacum L. cultivar Xanthi nc (Institute du Tabac, Bergerac, France) as described earlier (25).

Seeds of $N$. glutinosa L. were surface-disinfected and germinated on $1.2 \%(\mathrm{wt} / \mathrm{vol})$ water agar (Oxoid Ltd.) in a growth chamber (70\% relative humidity, $22^{\circ} \mathrm{C}$ with light at $80 \mu \mathrm{E} \mathrm{m}{ }^{-2} \mathrm{~s}^{-1}$ for $16 \mathrm{~h}$, and $18^{\circ} \mathrm{C}$ for $8 \mathrm{~h}$ in darkness) as described by Keel et al. (17). After 7 days, seedlings were transferred to modified Knop nutrient solution (17) solidified with $0.6 \%$ (wt/vol) agar (Oxoid Ltd.). The 5 -week-old seedlings were transplanted into the gnotobiotic system as previously described (17).

For the tobacco-TNV assay, $N$. tabacum cultivar Xanthi nc was grown from seeds on autoclaved quartz sand supplemented with modified Knop solution in a greenhouse for 4 weeks. The seedlings were then transplanted into autoclaved natural soil from Eschikon, Switzerland, amended with the bacterial strains.

DNA manipulations and cloning procedures. Small-scale preparations of plasmid DNA were carried out by the cetyltrimethylammonium bromide method (8), and large-scale preparations were performed using Qiagen-tips 100 (Qiagen AG, Basel, Switzerland). Restriction enzyme digestion, ligation, and agarose gel electrophoresis were performed by standard procedures (33). Restriction fragments were purified from agarose gels using the Geneclean II kit (Bio 101, Inc., Vista, CA). Transformation of $E$. coli and $P$. fluorescens was carried out by the classical $\mathrm{CaCl}_{2}$ procedure (33) or by electroporation (11).

Construction of the SA expression plasmids pME3377 and pME6127. A 3.3-kb SalI fragment carrying pchCBA of $P$. aeruginosa $(35,36)$ was inserted into the XhoI site of the broad-hostrange vector pVK100 (20) such that expression of the SA biosynthetic genes was controlled by the constitutive kanamycin promoter of the vector (Fig. 1A). A 54-bp SmaI DNA linker (5'CCCGGGGATCCGGTGATTGATTGAGCAAGCTTGCTCAATCAATCACCGGATCCCGGG-3') with translation stop signals in all three reading frames was inserted into the unique $S m a$ I site of the $p c h C$ gene to prevent the expression of this protein. The resulting plasmid, pME3377 (Fig. 1A), allowed iron-independent, constitutive expression of $p c h B A$.

A second expression plasmid, pME6127, was constructed using pME6000 (Fig. 1B). This new cloning vector was obtained by replacing a $0.3-\mathrm{kb}$ DraI fragment in the chloramphenicol resistance gene of the wide-host-range plasmid pBBR1MCS (22) with a T4 DNA polymerase-treated 2.8-kb HindIII-StuI fragment of
pVK100 specifying a tetracycline resistance tetR tetA. To obtain pME6127, a 5.65-kb SphI-ClaI fragment carrying the pchBA genes under the control of the constitutive kanamycin promoter was excised from pME3377 and cloned into pME6000 (Fig. 1B).

The vector pVK100, which was used for the construction of pME3377, is a derivative of RK2, a plasmid probably identical with RP1 $(3,20)$. The copy number of RP1 per chromosome equivalent has been estimated to be 3 in P. aeruginosa (16) and may be similar in $P$. fluorescens. For the plasmid pME6000, the direct precursor of pME6127, a copy number of 18 was determined per $P$. fluorescens chromosome equivalent (S. Heeb and D. Haas, unpublished data).

Extraction, detection, and quantification of siderophores and antibiotics. Single bacterial colonies were transferred to $20-\mathrm{ml}$ flasks containing $10 \mathrm{ml}$ of glycerol-casamino acids medium (GCM) (Difco casamino acids [Difco Laboratories], $5 \mathrm{~g}$; glycerol, $20 \mathrm{~g}$; $\mathrm{K}_{2} \mathrm{HPO}_{4} \cdot 3 \mathrm{H}_{2} \mathrm{O}, 0.75 \mathrm{~g} ; \mathrm{MgSO}_{4} \cdot 7 \mathrm{H}_{2} \mathrm{O}, 0.75 \mathrm{~g}$; and double-distilled $\mathrm{H}_{2} \mathrm{O}$, 1 liter) (C. Keel, unpublished data). After shaking the flasks on a rotary shaker (Lab-Shaker LSR, $110 \mathrm{rpm}, 2.5-\mathrm{cm}$ radius; Adolf Kühner AG, Basel, Switzerland) at $27^{\circ} \mathrm{C}$ for $12 \mathrm{~h}$, $10 \mu \mathrm{l}$ of the cultures was used to inoculate $20 \mathrm{ml}$ of GCM medium with or without $10 \mu \mathrm{M} \mathrm{FeCl}_{3}$ in $100-\mathrm{ml}$ Erlenmeyer flasks. The flasks were incubated at $27^{\circ} \mathrm{C}$ and shaken (rotary shaker; $110 \mathrm{rpm}$, $2.5-\mathrm{cm}$ radius) for $72 \mathrm{~h}$. The cultures were then acidified to $\mathrm{pH} 2$ with $1 \mathrm{M} \mathrm{HCl}$ and extracted with one volume of ethyl acetate. After evaporation of the organic phase, the dry residue was dissolved in $1 \mathrm{ml}$ of methanol and analyzed and then quantified by high-performance liquid chromatography (HPLC) as described before (26). SA was detected by UV absorption at $300 \mathrm{~nm}$, pyochelin at $254 \mathrm{~nm}$, 2,4-diacetylphloroglucinol at $270 \mathrm{~nm}$, and pyoluteorin at $313 \mathrm{~nm}$. The detection limit was $90 \mathrm{ng}$ for SA, $350 \mathrm{ng}$ for pyochelin, $20 \mathrm{ng}$ for 2,4-diacetylphloroglucinol, and $50 \mathrm{ng}$ for pyoluteorin. The metabolites produced were quantified according to standard curves prepared by injecting known amounts of commercial SA (Fluka AG, Buchs, Switzerland), pyochelin (28) purified from P. aeruginosa strain PAO1, 2,4-diacetylphloroglucinol synthesized according to Campbell and Coppinger (4), and pyoluteorin synthesized according to Cue et al. (5). The experiment was designed as a $2 \times 3$ factorial. The factors were iron and the different bacterial strains (wild type and two recombinants carrying plasmid pME3377 or pME6127). The experiment had five replications blocked over time.

Extraction of SA from the rhizosphere of tobacco grown in artificial soil. Tobacco plants were cultivated in sterile plant tissue culture containers (Wyss Samen und Pflanzen AG, Zuchwil, Solothurn, Switzerland) filled with $80 \mathrm{~g}$ of sterile artificial soil containing quartz sand of different sizes, quartz powder, and pure vermiculite clay (four plants per box) (17). Seven days before planting 5-week-old seedlings, bacteria were mixed with the soil to give a final concentration of $10^{7}$ cells per $\mathrm{g}$ of soil. Containers were arranged in a randomized complete block design with 39 replicates (one replicate $=$ one container with four plants) per treatment. After 3 weeks of incubation in a growth chamber with the same conditions as described above, plants were removed and loosely adhering soil was shaken gently from the roots. Roots of 20 plants with closely adhering soil were vigorously shaken for $30 \mathrm{~min}$ in $200 \mathrm{ml}$ of ethyl acetate (acidified to $\mathrm{pH} 2$ with $2 \mathrm{M}$ $\mathrm{HCl}$ ). Roots and soil were removed by filtering the extract through filter paper. The extracts of all replicates of a treatment were then pooled and brought to dryness in vacuo. The residues were redissolved in methanol and analyzed by HPLC as described before (26), except that a Nucleosil 120-5 C18 column $(4 \times 250 \mathrm{~mm}$; Macherey und Nagel, Düren, Switzerland) was used. The samples were eluted with a gradient of methanol from 20 to $42 \%$ (0 to $8 \mathrm{~min}$ ), 42 to $45 \%$ ( 8 to $14 \mathrm{~min}$ ), and 45 to $100 \%$ (14 to $25 \mathrm{~min}$ ) in $0.43 \%$ (vol/vol) $o$-phosphoric acid. The retention time of synthetic SA was $13.8 \mathrm{~min}$. The recovery of SA was estimated to be $45 \%$ based on results for artificial soil with added synthetic SA. The experiment was conducted three times. 
Extraction of SA from the rhizosphere of tobacco grown in autoclaved Eschikon soil. At the end of the last two induced-resistance experiments (experiments 3 and 4), all plants were removed from the pots. Loosely adhering soil was removed from the roots by shaking the plants gently by hand. Roots with closely adhering soil were extracted following the method of Bonsall et al. (2). Treatments (12 plants per treatment) were divided in subsamples of four plants, which were extracted together. After extraction with ethyl acetate, extracts of the subsamples were pooled and brought to dryness in vacuo. Residues were dissolved in methanol and analyzed by HPLC as described for the extraction from artificial soil.

Biocontrol of TNV. The tobacco-TNV assay described by Maurhofer et al. (25) was used for testing the ability of the different strains to induce systemic resistance. Surface-disinfected plastic pots were filled with $300 \mathrm{~g}$ of autoclaved soil from Eschikon mixed with $1 / 4$ volume of quartz sand. Bacteria were added to the mix to give a concentration of $10^{7}$ cells per $\mathrm{g}$ of soil. Two days later, a 4-week-old tobacco plant was transplanted into each pot. The pots were arranged in a randomized complete block design with 8 to 12 replicates, and one plants with one challenged leaf served as a replicate. After 6 weeks of incubation in a growth chamber with the same conditions as described above, all plants were challenge-inoculated on the youngest fully developed leaf. Plants of the systemic acquired resistance (SAR) control were induced with an initial TNV inoculation on a lower leaf 7 days prior to challenge inoculation. For TNV inoculations, the leaves were dusted with Carborundum, and four 50- $\mu$ l drops of a virus suspension were applied and gently rubbed on the leaf with a gauze pad. Virus suspensions were prepared from a tobacco leaf densely covered with TNV lesions. A 0.1 -g piece was taken and ground with $2 \mathrm{ml}$ of a $20 \mathrm{mM}$ phosphate buffer $(\mathrm{pH}$ 7.6) and then diluted 20 times using the same buffer. After 7 days, the number and size of lesions were assessed on challenge-inoculated leaves. The total necrotic area for each leaf was calculated by adding up the area of all the lesions on the leaf.

Root colonization and possible systemic colonization of the plants were examined as described by Maurhofer et al. (25). Population sizes of total aerobic bacteria were determined on tryptic soy agar plates (Difco tryptic soy agar [Difco Laboratories], $40 \mathrm{~g}$; and double-distilled $\mathrm{H}_{2} \mathrm{O}, 1$ liter), and populations of introduced bacteria were determined on King's B agar plates containing rifampicin. To test whether bacteria isolated from the roots still contained plasmid pME3377 or pME6127, the colonies were transferred by replica plating to King's B agar plates containing tetracycline. The experiment was conducted four times over a 4-month period.

Biocontrol of T. basicola. Suppression of black root rot of tobacco was tested in a gnotobiotic system as described by Keel et al. (17). Artificial soil was prepared by mixing quartz sand of different sizes, quartz powder, and pure vermiculite clay (17). Sixty grams of artificial soil was placed into $100-\mathrm{ml}$ flasks that were then sealed with cotton plugs and autoclaved at $121^{\circ} \mathrm{C}$ for $30 \mathrm{~min}$. Five milliliters of $P$. fluorescens suspensions was added to flasks to give $10^{7}$ cells of per $g$ of artificial soil. Control flasks were watered with the same volume of sterile double-distilled water. One day later, $5 \mathrm{ml}$ of a $T$. basicola suspension was mixed into the artificial soil with a sterile spatula to give a concentration of $2 \times$ $10^{4}$ endoconidia per $\mathrm{g}$ of soil. Seven days after the addition of the pathogen, one sterile-grown 5-week-old tobacco plant with four
A

pVK100 (23 kb)

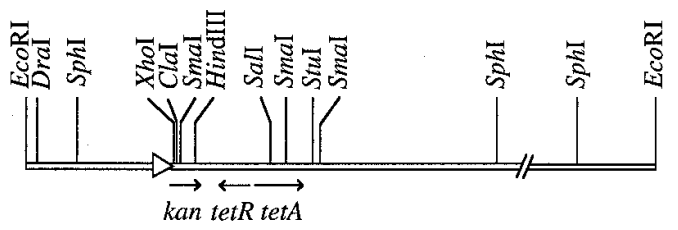

pME3377 (26.3 kb)

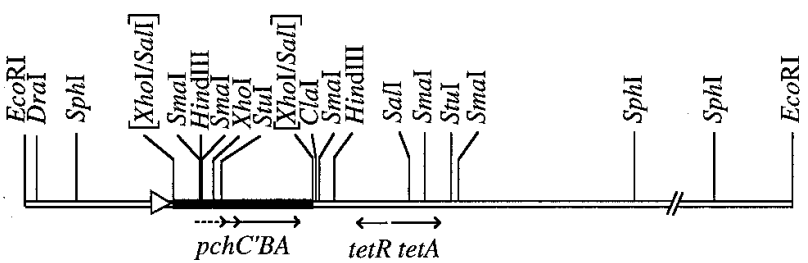

$1 \mathrm{~kb}$
B

pBBR1MCS (4.7 kb)

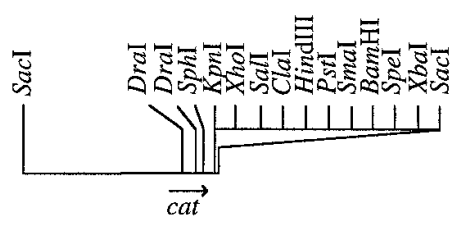

$\operatorname{pME6000~(7.2~kb)~}$

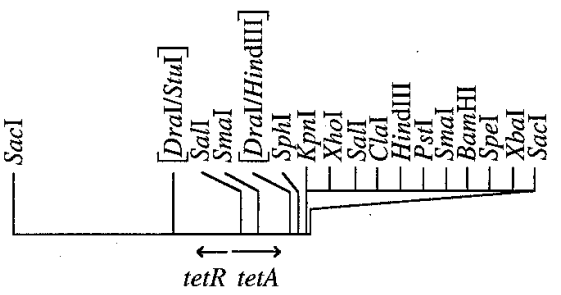

pME6127 (12.5 kb)

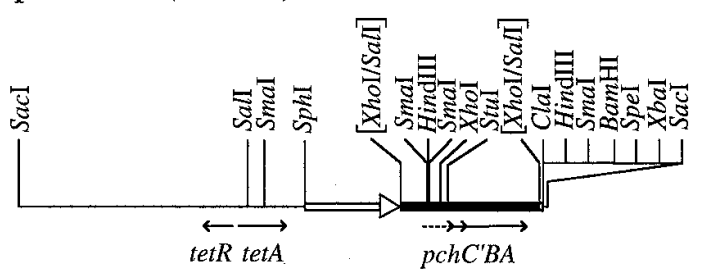

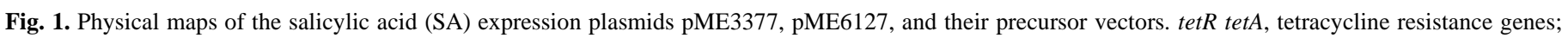

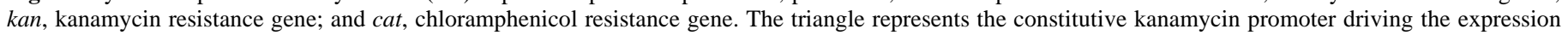

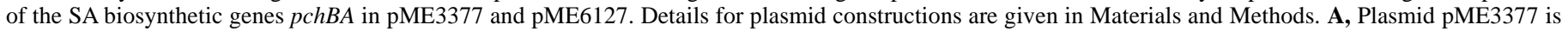
a derivative of pVK100. B, Plasmid pME6127 was constructed on the basis of the new cloning vector pME6000, which is derived from pBBR1MCS. 
leaves was transplanted into each flask and watered with $3 \mathrm{ml}$ of modified Knop nutrient solution. The flasks were arranged in a randomized complete block design, with eight replicates per treatment and one flask with one plant per replicate. Plants were grown for 3 weeks in a growth chamber under the conditions described above. Plants were removed from flasks by flooding with tap water and then washed to remove the rest of the soil. Plants were then weighed and assessed for disease severity and root colonization as described before (17). The experiment was conducted three times.

TABLE 1. Production of salicylic acid (SA) by Pseudomonas fluorescens strains P3 and CHA0 carrying the plasmids pME3377 and pME6127 in GCMv medium

\begin{tabular}{|c|c|c|c|c|}
\hline \multirow[b]{2}{*}{ Strain $^{w}$} & \multirow{2}{*}{$\begin{array}{l}\text { Iron } \\
\text { added }\end{array}$} & \multirow{2}{*}{$\begin{array}{l}\text { SA production } \\
\left(\mu \mathrm{g} / 10^{9} \mathrm{CFU}\right)\end{array}$} & \multicolumn{2}{|c|}{ ANOVA $^{x}$} \\
\hline & & & $F$ value & $P$ \\
\hline P3 & - & $<0.02 \mathrm{c}^{\mathrm{y}}$ & & \\
\hline P3/pME3377 & - & $0.8 \mathrm{~b}$ & & \\
\hline P3/pME6127 & - & $2.9 \mathrm{a}$ & & \\
\hline P3 & + & $<0.02 \mathrm{c}$ & & \\
\hline P3/pME3377 & + & $0.6 \mathrm{~b}$ & & \\
\hline P3/pME6127 & + & $2.8 \mathrm{a}$ & & \\
\hline \multicolumn{5}{|l|}{ ANOVA source } \\
\hline Strain P3 & & & 104.7 & 0.000 \\
\hline Iron & & & 0.201 & 0.658 \\
\hline Strain $\mathrm{P} 3 \times$ iron & & & 0.053 & 0.948 \\
\hline CHA0 & - & $11.2 \mathrm{a}$ & & \\
\hline CHA0/pME3377 & - & $10.2 \mathrm{a}$ & & \\
\hline CHA0/pME6127 & - & $12.3 \mathrm{a}$ & & \\
\hline CHAO & + & $<0.02 \mathrm{c}^{\mathrm{z}}$ & & \\
\hline CHA0/pME3377 & + & $1.3 \mathrm{~b}^{\mathrm{z}}$ & & \\
\hline CHA0/pME6127 & + & $5.3 \mathrm{a}^{\mathrm{z}}$ & & \\
\hline \multicolumn{5}{|l|}{ ANOVA source } \\
\hline Strain CHA0 & & & 12.0 & 0.000 \\
\hline Iron & & & 231.2 & 0.000 \\
\hline Strain $\mathrm{CHA} 0 \times$ iron & & & 4.074 & 0.030 \\
\hline
\end{tabular}

${ }^{v} \mathrm{GCM}=$ glycerol-casamino acids.

${ }^{w}$ Bacteria were grown in GCM medium with or without the addition of 10 $\mu \mathrm{M} \mathrm{FeCl}{ }_{3}$ at $27^{\circ} \mathrm{C}$ for $72 \mathrm{~h}$. SA was extracted from the culture medium with ethyl acetate.

$x$ ANOVA $=$ analysis of variance.

${ }^{y}$ Each value is the mean of five repetitions. Values in the same column followed by the same letter are not significantly different at $P=0.05$ according to Fisher's protected least significant difference test. For P3 and its derivatives, all means in the column were compared. For CHA0 and its derivatives, means of treatments with iron and means of treatments without iron were compared separately because of the significant strain $\times$ iron interaction.

$\mathrm{z}$ These means were compared with each other.
Statistics. For production of SA in vitro (Table 1), the values presented in Table 1 are the means of five replications. Because this experiment was a $2 \times 3$ factorial, data were first analyzed by a two-way analysis of variance (Systat version 7.0; Systat Inc., Evanston, IL) and then by Fisher's least significant difference (LSD) test (Systat Inc.). For biocontrol of TNV (Table 2) and $T$. basicola (Table 3), experiments were analyzed separately using Fisher's LSD test (Systat Inc.) after a significant $F$ test $(P \leq 0.05)$ (Systat Inc.). Values of the total necrotic area (Table 2) were log normally distributed and, therefore, log-transformed prior to statistical analysis. For black root rot severity (percentage of root surface darkened by chlamydospores) (Table 3), values were transformed to arcsines prior to statistical analysis.

\section{RESULTS}

Production of SA, pyochelin, and antibiotics by Pseudomonas spp. expressing the pchBA genes. Recombinant pseudomonads producing SA constitutively were constructed using the vectors pVK100 and pME6000 (Fig. 1). The production of SA, pyochelin, and antibiotics by strains CHA0 and P3 transformed with either pME3377 (pVK100pchBA $\left.A^{+}\right)$or pME6127 (pME6000pchBA $\left.A^{+}\right)$ was compared with the production of these metabolites by the plasmid-free strains in GCM. Introduction of either plasmid rendered the SA-negative strain P3 capable of producing SA (Table 1). Similar amounts of SA were obtained with and without added iron, confirming iron-independent expression of $p c h B A$ by both expression plasmids. Strain P3/pME6127 produced significantly more SA than did strain P3/pME3377, possibly reflecting the different plasmid copy numbers. However, SA production of P3/pME6127 remained about four times lower than SA production of strain CHA0 under iron-limited conditions (Table 1). For strain CHA0 and its derivatives carrying $p c h B A$, the addition of iron to the growth medium had a significant influence on SA production (Table 1). Under iron-limited conditions, the high amount of SA produced by CHA0 was not increased by the introduction of pME3377 or pME6127. In the presence of added iron, SA production was repressed in CHA0, but was detectable in CHA0/pME3377 and CHA0/pME6127 (Table 1). The amount of SA produced by CHA0/pME6127 in the presence of added iron was greater than that produced by CHA0/pME3377, but still about two times smaller than the amount of SA produced by the wild type under ironlimited conditions.

The plasmids did not influence the amounts of pyochelin produced by strain CHA0. In the absence of iron for strain CHA0 and its derivatives carrying $p c h B A$, which produced 9.8 to $12.9 \mu \mathrm{g}$ of

TABLE 2. Induction of systemic resistance in tobacco against tobacco necrosis virus (TNV) by Pseudomonas fluorescens strains P3 and CHA0 carrying the salicylic acid (SA) biosynthetic genes $p c h B A$

\begin{tabular}{|c|c|c|c|c|c|c|c|c|}
\hline \multirow[b]{2}{*}{ Treatment $^{\mathrm{x}}$} & \multicolumn{2}{|c|}{ Experiment 1} & \multicolumn{2}{|c|}{ Experiment 2} & \multicolumn{2}{|c|}{ Experiment 3} & \multicolumn{2}{|c|}{ Experiment 4} \\
\hline & TNA $^{y}$ & $\mathrm{LD}^{\mathrm{y}}$ & TNA & LD & TNA & LD & TNA & LD \\
\hline TNV control & $465 \mathrm{a}^{\mathrm{z}}$ & $2.5 \mathrm{a}$ & $172 \mathrm{a}$ & $2.1 \mathrm{a}$ & $56 \mathrm{a}$ & $2.0 \mathrm{a}$ & $39 \mathrm{a}$ & $1.9 \mathrm{a}$ \\
\hline SAR control & $55 \mathrm{de}$ & $1.0 \mathrm{~d}$ & $5 \mathrm{~d}$ & $0.6 \mathrm{e}$ & $1 \mathrm{~d}$ & $0.7 \mathrm{~d}$ & $3 \mathrm{c}$ & $0.6 \mathrm{e}$ \\
\hline \multicolumn{9}{|l|}{ Roots colonized with: } \\
\hline P3 & $288 \mathrm{ab}$ & $2.5 \mathrm{a}$ & $82 \mathrm{ab}$ & $1.8 \mathrm{~b}$ & $20 \mathrm{~b}$ & $1.5 \mathrm{~b}$ & $11 \mathrm{~b}$ & $1.7 \mathrm{ab}$ \\
\hline P3/pME3377 & $40 \mathrm{e}$ & $2.5 \mathrm{a}$ & $53 \mathrm{~b}$ & $1.6 \mathrm{bc}$ & $13 \mathrm{~b}$ & $1.3 \mathrm{bc}$ & $2 \mathrm{c}$ & $0.9 \mathrm{de}$ \\
\hline P3/pME6127 & $48 \mathrm{de}$ & $2.0 \mathrm{bc}$ & $24 \mathrm{~d}$ & $1.2 \mathrm{~d}$ & $8 \mathrm{c}$ & $1.1 \mathrm{c}$ & $2 \mathrm{c}$ & $1.2 \mathrm{~cd}$ \\
\hline CHAO & $93 \mathrm{~cd}$ & $2.0 \mathrm{bc}$ & $55 \mathrm{~b}$ & $1.5 \mathrm{c}$ & $23 \mathrm{~b}$ & $1.4 \mathrm{~b}$ & $11 \mathrm{~b}$ & $1.3 \mathrm{bcd}$ \\
\hline CHA0/pME3377 & $150 \mathrm{bc}$ & $1.9 \mathrm{c}$ & $35 \mathrm{c}$ & $1.5 \mathrm{c}$ & $21 \mathrm{~b}$ & $1.3 \mathrm{bc}$ & $20 \mathrm{ab}$ & $1.8 \mathrm{a}$ \\
\hline CHA0/pME6127 & $262 \mathrm{bc}$ & $2.3 \mathrm{ab}$ & $67 \mathrm{ab}$ & $1.4 \mathrm{~cd}$ & $15 \mathrm{~b}$ & $1.3 \mathrm{bc}$ & $10 \mathrm{~b}$ & $1.5 \mathrm{abc}$ \\
\hline
\end{tabular}

$\mathrm{x}$ 'Xanthi nc' plants were grown for 6 weeks and then challenge-inoculated with TNV. Plants of the TNV control were not induced prior to challenge inoculation with TNV. Plants of the systemic acquired resistance (SAR) control were induced with a TNV inoculation on a lower leaf 7 days prior to challenge inoculation. P3 = SA-negative wild-type strain; CHA0 = SA-producing wild-type strain; P3/pME3377, P3/pME6127, CHA0/pME3377, and CHA0/pME6127 = transgenic strains carrying the SA biosynthetic genes pchBA.

y $\mathrm{TNA}=$ Total necrotic area per leaf $\left(\mathrm{mm}^{2}\right)$, and $\mathrm{LD}=$ lesion diameter $(\mathrm{mm})$.

${ }^{\mathrm{z}}$ Values are the mean of 8 (experiments 1 and 2) or 12 (experiments 3 and 4) plants per treatment. Analysis of variance showed that the treatment effect was highly significant $(P \leq 0.001)$ in all experiments. Values in the same column followed by the same letter are not significantly different according to Fisher's protected least significant difference test $(P=0.05)$. TNA values were log-transformed prior to statistical analysis. 
pyochelin per $\log 9 \mathrm{CFU}$, the addition of $10 \mu \mathrm{M} \mathrm{FeCl}_{3}$ to the medium resulted in much lower pyochelin production $(0.2$ to $0.3 \mu \mathrm{g} /$ $\log 9 \mathrm{CFU}$ ). Strain P3 and its derivatives carrying $p c h B A$ did not produce any pyochelin. Introduction of $p c h B A$ into strain CHA0 had no influence on the production of the antibiotics 2,4-diacetylphloroglucinol and pyoluteorin (data not shown). The addition of $10 \mu \mathrm{M} \mathrm{FeCl}_{3}$, however, enhanced the production of 2,4-diacetylphloroglucinol by strain CHA0 from 0.5 to $8.8 \mu \mathrm{g} / \log 9 \mathrm{CFU}$ and pyoluteorin from an undetectable level to $0.5 \mu \mathrm{g} / \log 9 \mathrm{CFU}$. Strain P3 and its derivatives carrying $p c h B A$ did not produce any 2,4diacetylphloroglucinol or pyoluteorin. Introduction of the plasmids did not influence the growth rates of strains P3 and CHA0. At the time of extraction, the cell densities of the two wild-type strains and their derivatives carrying $p c h B A$ were between $\log 8.8$ and 9.0 $\mathrm{CFU} / \mathrm{ml}$ in the absence of added iron and between $\log 9.4$ and 9.5 $\mathrm{CFU} / \mathrm{ml}$ in the presence of added iron.

Production of SA in the rhizosphere of tobacco. After 3 weeks of growth in artificial soil inoculated with strain CHA0 or CHA0/ pME3377, roots with adhering soil were extracted with ethyl acetate. The wild-type strain CHA0 produced $8.5 \pm 7.5 \mathrm{ng}$ of SA per $\mathrm{g}$ of roots with adhering rhizosphere soil and $45.3 \pm 20.4 \mathrm{ng}$ of SA per plant. Plasmid pME3377 enhanced SA production by CHA0 in the rhizosphere by a factor of three. Strain CHA0/pME3377 produced $30.7 \pm 7.3 \mathrm{ng}$ of SA per $\mathrm{g}$ of roots with adhering rhizosphere soil and $145.1 \pm 19.9 \mathrm{ng}$ of SA per plant.

After 7 weeks of growth in Eschikon soil inoculated with strains CHA0, P3, and their derivatives carrying pchBA, roots from tobacco plants with adhering rhizosphere soil were extracted with acetone and ethyl acetate. No SA could be detected in the rhizosphere of plants grown in soil inoculated with either strain.

Protection of tobacco against TNV. The influence of the plasmids pME3377 and pME6127 in strains P3 and CHA0 on ISR in tobacco against TNV was tested using 'Xanthi nc' plants grown in autoclaved Eschikon soil that had been inoculated with these bacterial strains. Plants induced by an initial TNV inoculation on a lower leaf (SAR control) were nearly completely resistant to the challenge inoculation in all experiments (Table 2). Strain P3 gave partial protection against TNV and reduced total necrotic leaf area by 38 to $73 \%$ (significant in experiments 3 and 4). Plasmid pME6127 significantly improved the ability of strain P3 to induce resistance in all four experiments. Compared with plants colonized by strain $\mathrm{P} 3$, the total necrotic area of plants colonized by strain P3/pME6127 was reduced by 60 to $83 \%$, and the lesion diameter was reduced by 20 to $33 \%$ (Table 2). Plants protected by strain P3/pME3377 showed a significantly (83\%) reduced total necrotic leaf area compared with plants protected by the wild type in experiments 1 and 4 . Strain CHA0 induced resistance against the virus in all experiments and reduced the total necrotic area by 59 to $80 \%$ and lesion diameter by 20 to $32 \%$. Strains CHA0/pME3377 and $\mathrm{CHA}$ /pME6127 did not differ from the parental strain in their ability to induce resistance (Table 2). Neither the two wildtype strains P3 and CHA0 nor their derivatives carrying pchBA reduced the size of the lesions to the extent found in the SAR control plants. After 7 weeks, mean population densities of all bacterial strains ranged from $\log 5.1$ to $5.3 \mathrm{CFU}$ per $\mathrm{g}$ of tobacco roots, and 83 to $90 \%$ of the bacteria still contained plasmid pME3377 or pME6127. Population sizes of total aerobic bacteria ranged from $\log 7.8$ to $8.2 \mathrm{CFU} / \mathrm{g}$ of tobacco roots in all treatments. None of the strains inoculated was found inside the stems or leaves.

Suppression of black root rot under gnotobiotic conditions. Strains P3 and CHA0 and their transformants carrying pchBA were tested for the ability to suppress black root rot of tobacco in a gnotobiotic system. In the absence of the pathogen, neither the two wildtype strains $\mathrm{P} 3$ and $\mathrm{CHA} 0$ nor their derivatives carrying pchBA influenced plant growth. Fresh weights of plants grown in the presence of the bacterial strains alone ranged from 592 to $720 \mathrm{mg}$. Strain P3 gave in one experiment out of three a significant protection against Thielaviopsis, but only in terms of plant fresh weight (Table 3). In all experiments, the root infection of plants inoculated with strain P3 was as severe as that of the control. In contrast to plants grown in the presence of the wild-type strain P3, in all three experiments, plants grown in presence of strains P3/pME3377 and P3/pME6127 had significantly higher fresh weights than did control plants. The difference in fresh weight between plants protected by the wild type and those protected by the recombinant strains, however, was only significant in one case (strain P3/pME6127, experiment 3). The root surface infection of plants grown in the presence of strains P3/pME3377, P3/pME6127, or the parental strain was similar (Table 3). Plants protected by strain CHA0 showed 170 to $280 \%$ higher fresh weights and 68 to $78 \%$ lower root infection compared with the control (Table 3). Neither plasmid pME3377 nor plasmid pME6127 significantly improved the disease suppressiveness of strain CHA0.

At the end of the experiments, strain $\mathrm{CHA} 0$ and its derivatives were recovered from the roots at population densities ranging from $\log 8.2$ to $8.5 \mathrm{CFU} / \mathrm{g}$ of root fresh weight; strain P3 and its derivatives were recovered at densities ranging from $\log 8.4$ to 8.9 $\mathrm{CFU} / \mathrm{g}$ of root fresh weight. In all treatments, 70 to $80 \%$ of the bacteria still contained the plasmid pME3377 or pME6127.

\section{DISCUSSION}

Expression of the SA biosynthetic genes $p c h B A$ in the SAnegative, root-colonizing strain P3 significantly improved its abil-

TABLE 3. Suppression of black root rot of tobacco by Pseudomonas fluorescens strains P3 and CHA0 carrying the salicylic acid (SA) biosynthetic genes pchBA

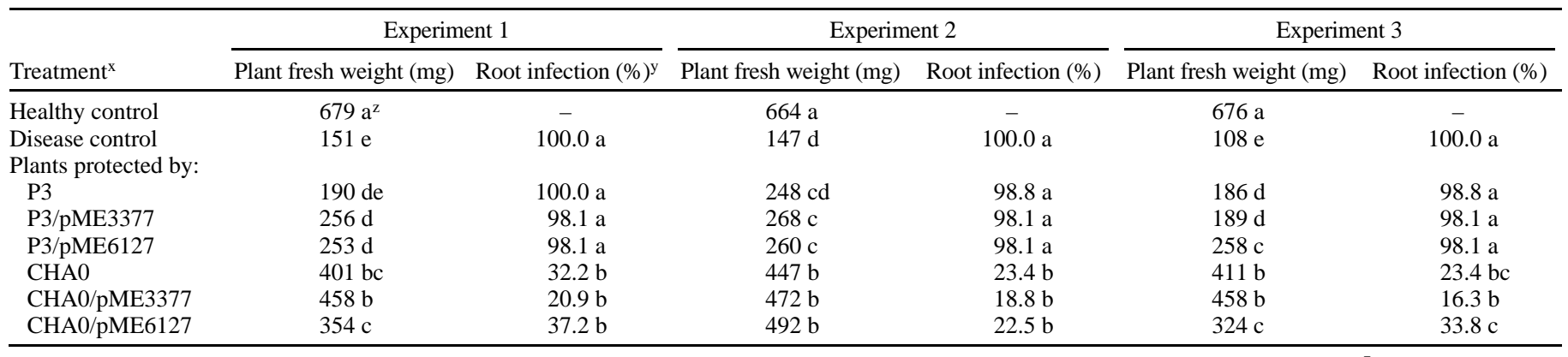

${ }^{\mathrm{x}}$ Nicotiana glutinosa plants were grown in artificial soil for 3 weeks under gnotobiotic conditions. The soil was amended with bacteria $\left(10^{7}\right.$ cells per g) 8 days, and with Thielaviopsis basicola $\left(2 \times 10^{4}\right.$ endoconidia per $\left.\mathrm{g}\right) 7$ days, before addition of the plant. P3 = SA-negative wild-type strain; CHA0 $=$ SA-producing wild-type strain; P3/pME3377, P3/pME6127, CHA0/pME3377, and CHA0/pME6127 = transgenic strains carrying the SA biosynthetic genes pchBA. In the healthy control, the soil was not amended with bacteria or T. basicola. In the disease control the soil was amended only with $T$. basicola.

y Percentage of root surface darkened by chlamydospores.

${ }^{\mathrm{z}}$ Mean of eight replicates with one flask containing one plant per replicate. Analysis of variance showed that the treatment effect was highly significant $(P \leq$ 0.001) in all experiments. Values in the same column followed by the same letter are not significantly different according to Fisher's protected least significant difference test $(P=0.05)$. Values of the root infection were arcsin-transformed prior to statistical analysis. 
ity to induce systemic resistance against TNV in tobacco. In an earlier study (40), we demonstrated that the suppression of black root rot by strain P3 can be improved by inserting into it the hydrogen cyanide biosynthetic genes of strain CHA0. The biocontrol activity of other pseudomonads has been improved by the introduction of genes required for the production of antifungal antibiotics or chitinase $(12,13,21,26,34)$. However, transgenic bacteria do not always outperform the parental strains. For instance, introducing pchBA into strain P3 had little or no effect on the suppression of black root rot of tobacco, suggesting that bacterial SA production in the rhizosphere is not a major factor in the suppression of this disease. Derivatives of strain CHA0 carrying either plasmid pME3377 or pME6127 showed iron-independent SA production in vitro and an enhanced SA production (CHA0/pME3377) in the rhizosphere of tobacco grown in a gnotobiotic system. However, protection of roots against black root rot was not improved by SA overexpression in the tobacco rhizosphere, and derivatives of strain CHA0 carrying $p c h B A$ did not show improved protection against TNV. This finding does not exclude the possibility that SA production plays a role in disease suppression by strain CHA0. We suggest that the amount of SA produced by strain CHAO in the rhizosphere is already sufficient to induce systemic resistance and that increasing this amount does not increase the level of ISR. However, we could not detect the presence of SA in the rhizosphere of tobacco plants grown in Eschikon soil, probably due to adsorbance of SA to organic matter or the clay minerals in this soil. Leeman et al. (23) showed that treatment of radish root tips with SA-induced systemic resistance against Fusarium wilt independently of the SA concentration (100 fg to $100 \mu \mathrm{g}$ per plant) used. In an earlier study (25), we found that strain CHA400, a pyoverdine-negative mutant of strain CHA0, lost part of its ability to induce resistance in tobacco against TNV. The remaining ISR capacity could be due to SA production or to other, as yet unidentified, bacterial traits.

The newly constructed cloning vector pME6000 (Fig. 1B) used here is a derivative of pBR1MCS (22), which replicates stably in Gram-negative bacteria including Vibrio, Escherichia, and Rhizobium. We found that pME6000 is maintained in P. fluorescens CHA0 for up to 100 generations without antibiotic selection in vitro (S. Heeb and D. Haas, unpublished data), making this vector suitable for environmental studies. The fact that pME6000 has about 18 copies per chromosome equivalent in $P$. fluorescens can be an advantage whenever high gene expression is required in recombinant strains.

In several systems, evidence is now accumulating for a role of bacterial SA in ISR. Our experiments have shown that $P$. fluorescens strain P3 engineered to produce SA had an improved ability to induce systemic resistance against TNV in tobacco. In addition, De Meyer and Höfte (9) found that SA-negative mutants of $P$. aeruginosa 7NSK2 lost their ability to induce systemic resistance against $B$. cinerea in bean. Finally, Leeman et al. (23) attributed the capacity of $\mathrm{O}$-antigenic sidechain-negative mutants of $P$. fluorescens strains WCS374 and WCS417 to induce systemic resistance against Fusarium wilt of radish at low, but not at high, iron availability to the production of SA. In contrast to these examples, Press et al. (31) suggested that SA production by $S$. marcescens 90-166 was not important in the induction of systemic resistance in cucumber and tobacco, because SA-negative mutants of strain 90-166 induced the same level of resistance in cucumber, wildtype tobacco, and NahG-tobacco (the NahG gene encodes the enzyme salicylate hydroxylase that degrades SA) expressing salicylate hydroxylase as the wild type. A role of SA in PGPRmediated ISR seems to depend on the biocontrol strain and maybe also on the plant species. Van Wees et al. (39) showed that the capacity of PGPR strains to induce resistance can be specific not only for certain plant species, but even for ecotypes. A mutant lacking the O-antigenic sidechain of lipopolysaccharide lost its ability to induce resistance in one plant species, but still elicited
ISR in another (39). Moreover, some PGPR strains including CHA0 induce PR proteins in plants $(15,25,45)$, while others do not, although plants can exhibit systemic resistance $(14,29)$. ISR mediated by root-colonizing bacteria appears to involve multiple mechanisms, depending on the biocontrol strains and host plants.

\section{ACKNOWLEDGMENTS}

This study was supported by the Swiss National Foundation for Scientific Research (project 31-32473.91) and the Swiss Federal Office for Education and Science (EU project IMPACT 2, BIO4CT960027). We thank B. Duffy for the critical reading of the manuscript.

\section{LITERATURE CITED}

1. Alström, S. 1991. Induction of disease resistance in common bean susceptible to halo blight bacterial pathogen after seed bacterization with rhizosphere pseudomonads. J. Gen. Appl. Microbiol. 37:495-501.

2. Bonsall, R. F., Weller, D. M., and Thomashow, L. S. 1997. Quantification of 2,4-diacetylphloroglucinol produced by fluorescent Pseudomonas spp. in vitro and in the rhizosphere of wheat. Appl. Environ. Microbiol. 63:951-955.

3. Burkhardt, H. J., Riess, G., and Pühler, A. 1979. Relationship of group P1 plasmids revealed by heteroduplex experiments: RP1, RP4, R68 and RK2 are identical. J. Gen. Microbiol. 114:341-348.

4. Campbell, T. W., and Coppinger, G. M. 1951. The spectrophotometric examination of some derivatives of pyrogallol and phloroglucinol. J. Am. Chem. Soc. 73:2708-2712.

5. Cue, B. W., Dirlam, J. P., Czuba, L. J., and Windisch, W. W. 1981. A practical synthesis of pyoluteorin. J. Heterocyclic Chem. 18:191-192.

6. Défago, G., Berling, C.-H., Burger, U., Haas, D., Kahr, G., Keel, C., Voisard, C., Wirthner, P., and Wüthrich, B. 1990. Suppression of black root rot of tobacco and other root diseases by strains of Pseudomonas fluorescens: Potential applications and mechanisms. Pages 93-108 in: Biological Control of Soilborne Plant Pathogens. D. Hornby, R. J. Cook, Y. Henis, W. H. Ko, A. D. Rovira, B. Schippers, and P. R. Scott, eds. CAB International, Oxon, United Kingdom.

7. Défago, G., and Haas, D. 1990. Pseudomonads as antagonists of soilborne plant pathogens: Mode of action and genetic analysis. Pages 249291 in: Soil Biochemistry. Vol. 6. J. M. Bollag and G. Stotzky, eds. Marcel Dekker, Inc., New York.

8. Del Sal, G., Manfioletti, G., and Schneider, C. 1988. A one-tube plasmid DNA mini-preparation suitable for sequencing. Nucleic Acids Res. 16:9878.

9. De Meyer, G., and Höfte, M. 1997. Salicylic acid produced by the rhizobacterium Pseudomonas aeruginosa 7NSK2 induces resistance to leaf infection by Botrytis cinerea on bean. Phytopathology 87:588-593.

10. Enyedi, A. J., Yalpani, N., Silverman, P., and Raskin, I. 1992. Localization, conjugation, and function of salicylic acid in tobacco during the hypersensitive reaction to tobacco mosaic virus. Proc. Natl. Acad. Sci. U.S.A. 89:2480-2484.

11. Farinha, M. A., and Kropinski, A. M. 1990. High efficiency electroporation of Pseudomonas aeruginosa using frozen cell suspensions. FEMS (Fed. Eur. Microbiol. Soc.) Microbiol. Lett. 70:221-226.

12. Fenton, A. M., Stephens, P. M., Crowley, J., O’Callaghan, M., and O'Gara, F. 1992. Exploitation of gene(s) involved in 2,4-diacetylphloroglucinol biosynthesis to confer a new biocontrol capability to a Pseudomonas strain. Appl. Environ. Microbiol. 58:3873-3878.

13. Hara, H., Bangera, M., Kim, D.-S., Weller, D. M., and Thomashow, L. S. 1994. Effects of transfer and expression of antibiotic biosynthetic genes on biological control activity of fluorescent pseudomonads. Pages 247-249 in: Improving Plant Productivity with Rhizosphere Bacteria. M. H. Ryder, P. M. Stephens, and G. D. Bowen, eds. CSIRO, Glen Osmond, Australia.

14. Hoffland, E., Pieterse, C. M. J., Bik, L., and van Pelt, J. A. 1995. Induced systemic resistance in radish is not associated with accumulation of pathogenesis-related proteins. Physiol. Mol. Plant Pathol. 46:309-320.

15. Hynes, R. K., and Lazarovits, G. 1989. Effect of seed treatment with plant growth promoting rhizobacteria on the protein profiles of intercellular fluids from bean and tomato leaves. Can. J. Plant Pathol. 11:191.

16. Itoh, Y., Watson, J. M., Haas, D., and Leisinger, T. 1984. Genetic and molecular characterization of the Pseudomonas plasmid pVS1. Plasmid 11:206-220.

17. Keel, C., Voisard, C., Berling, C. H., Kahr, G., and Défago, G. 1989. Iron sufficiency, a prerequisite for the suppression of tobacco black root rot by Pseudomonas fluorescens strain CHA0 under gnotobiotic conditions. Phytopathology 79:584-589.

18. King, E. O., Ward, M. K., and Raney, D. E. 1954. Two simple media for the demonstration of pyocyanin and fluorescein. J. Lab. Clin. Med. 44: 
301-307.

19. Kloepper, J. W., Tuzun, S., and Kuc, J. A. 1992. Proposed definitions related to induced disease resistance. Biocontrol Sci. Technol. 2:349-351.

20. Knauf, V. C., and Nester, E. W. 1982. Wide host range cloning vectors: A cosmid clone bank of an Agrobacterium Ti plasmid. Plasmid 8:45-54.

21. Koby, S., Schickler, H., Chet, I., and Oppenheim, A. B. 1994. The chitinase encoding Tn7-based chiA gene endows Pseudomonas fluorescens with the capacity to control plant pathogens in soil. Gene 147:81-83.

22. Kovach, M. E., Phillips, R. W., Elzer, P. H., Roop, R. M., II, and Peterson, K. M. 1994. pBBR1MCS: A broad-host-range cloning vector. BioTechniques 16:800-802.

23. Leeman, M., den Ouden, F. M., van Pelt, J. A., Dirkx, F. P. M., Steijl, H., Bakker, P. A. H. M., and Schippers, B. 1996. Iron availability affects induction of systemic resistance to Fusarium wilt of radish by Pseudomonas fluorescens. Phytopathology 86:149-155.

24. Leeman, M., Van Pelt, J. A., Den Ouden, F. M., Heinsbroek, M., Bakker, P. A. H. M., and Schippers, B. 1995. Induction of systemic resistance against Fusarium wilt of radish by lipopolysaccharides of Pseudomonas fluorescens. Phytopathology 85:1021-1027.

25. Maurhofer, M., Hase, C., Meuwly, P., Métraux, J.-P., and Défago, G. 1994. Induction of systemic resistance of tobacco to tobacco necrosis virus by the root-colonizing Pseudomonas fluorescens strain CHA0: Influence of the gacA gene and of pyoverdine production. Phytopathology 84:139-146.

26. Maurhofer, M., Keel, C., Schnider, U., Voisard, C., Haas, D., and Défago, G. 1992. Influence of enhanced antibiotic production in Pseudomonas fluorescens strain CHA0 on its disease suppressive capacity. Phytopathology 82:190-195.

27. Meyer, J.-M., Azelvandre, P., and Georges, C. 1992. Iron metabolism in Pseudomonas: Salicylic acid, a siderophore of Pseudomonas fluorescens CHA0. Bio Factors 4:23-27.

28. Meyer, J.-M., Hohnadel, D., and Hallé, F. 1989. Cepabactin from Pseudomonas cepacia, a new type of siderophore. J. Gen. Microbiol. 135: 1479-1487.

29. Pieterse, C. M. J., van Wees, S. C. M., Hoffland, E., van Pelt, J. A., and van Loon, L. C. 1996. Systemic resistance in arabidopsis induced by biocontrol bacteria is independent of salicylic acid accumulation and pathogenesis-related gene expression. Plant Cell 8:1225-1237.

30. Press, C. M., and Kloepper, J. W. 1996. Role of bacterial cell wall and membrane constituents in PGPR-mediated induced systemic resistance of cucumber. (Abstr.) Phytopathology 86:S48.

31. Press, C. M., Wilson, M., Tuzun, S., and Kloepper, J. W. 1997. Salicylic acid produced by Serratia marcescens $90-166$ is not the primary determinant of induced systemic resistance in cucumber or tobacco. Mol. Plant-Microbe Interact. 10:761-768
32. Raupach, G. S., Liu, L., Murphy, J. F., Tuzun, S., and Kloepper, J. W. 1996. Induced systemic resistance in cucumber and tomato against cucumber mosaic cucumovirus using plant growth-promoting rhizobacteria (PGPR). Plant Dis. 80:891-894.

33. Sambrook, J., Fritsch, E. F., and Maniatis, T. 1989. Molecular Cloning: A Laboratory Manual, 2nd ed. Cold Spring Harbor Laboratory, Cold Spring Harbor, NY.

34. Schnider, U., Keel, C., Blumer, C., Troxler, J., Défago, G., and Haas, D. 1995. Amplification of the housekeeping sigma factor in Pseudomonas fluorescens $\mathrm{CHA0}$ enhances antibiotic production and improves biocontrol abilities. J. Bacteriol. 177:5387-5392.

35. Serino, L., Reimmann, C., Baur, H., Beyeler, M., Visca, P., and Haas, D. 1995. Structural genes for salicylic acid biosynthesis from chorismate in Pseudomonas aeruginosa. Mol. Gen. Genet. 249:217-228.

36. Serino, L., Reimmann, C., Visca, P., Beyeler, M., Della Chiesa, V., and Haas, D. 1997. Biosynthesis of pyochelin and dihydroaeruginoic acid requires the iron-regulated pchDCBA operon in Pseudomonas aeruginosa. J. Bacteriol. 179:248-257.

37. Stutz, E. W., Défago, G., and Kern, H. 1986. Naturally occurring fluorescent pseudomonads involved in suppression of black root rot of tobacco. Phytopathology 76:181-185.

38. van Peer, R., Niemann, G. J., and Schippers, B. 1991. Induced resistance and phytoalexin accumulation in biological control of Fusarium wilt of carnation by Pseudomonas sp. strain WCS417r. Phytopathology 81:728-734.

39. Van Wees, S. C. M., Pieterse, C. M. J., Trijssenaar, A., Van 't Westende, Y. A. M., Hartog, F., and Van Loon, L. C. 1997. Differential induction of systemic resistance in Arabidopsis by biocontrol bacteria. Mol. PlantMicrobe Interact. 10:716-724.

40. Voisard, C., Keel, C., Haas, D., and Défago, G. 1989. Cyanide production by Pseudomonas fluorescens helps suppress black root rot of tobacco under gnotobiotic conditions. EMBO (Eur. Mol. Biol. Organ.) J. 8:351-358.

41. Ward, E. R., Uknes, S. J., Williams, S. C., Dincher, S. S., Wiederhold, D. L., Alexander, D. C., Ahl-Goy, P., Métraux, J.-P., and Ryals, J. A. 1991. Coordinate gene activity in response to agents that induce systemic acquired resistance. Plant Cell 3:1085-1094.

42. Wei, G., Kloepper, J. W., and Tuzun, S. 1991. Induction of systemic resistance of cucumber to Colletotrichum orbiculare by select strains of plant growth-promoting rhizobacteria. Phytopathology 81:1508-1512.

43. Weller, D. M. 1988. Biological control of soilborne plant pathogens in the rhizosphere with bacteria. Annu. Rev. Phytopathol. 26:379-407.

44. White, R. F. 1979. Acetylsalicylic acid (aspirin) induces resistance to tobacco mosaic virus in tobacco. Virology 99:410-412.

45. Zdor, R. E., and Anderson, A. J. 1992. Influence of root colonizing bacteria on the defense responses of bean. Plant Soil 140:99-107. 